\title{
IKK is a therapeutic target in KRAS-induced lung cancer with disrupted p53 activity
}

\author{
Daniela S. Bassères ${ }^{1}$, Aaron Ebbs ${ }^{2}$, Patricia C. Cogswell ${ }^{2}$ and Albert S. Baldwin ${ }^{2,3}$ \\ ${ }^{1}$ Department of Biochemistry, Chemistry Institute, University of São Paulo, São Paulo, SP, Brazil; \\ ${ }^{2}$ Lineberger Comprehensive Cancer Center, University of North Carolina, Chapel Hill, NC; \\ ${ }^{3}$ Department of Biology, University of North Carolina, Chapel Hill, NC. \\ Correspondence to: Albert S. Baldwin, email: albert_baldwin@med.unc.edu
}

Keywords: Lung cancer, KRAS, NF-KB, IKK, p53

Received: July 2, $2013 \quad$ Accepted: April 21, $2014 \quad$ Published: April 21, 2014

This is an open-access article distributed under the terms of the Creative Commons Attribution License, which permits unrestricted use, distribution, and reproduction in any medium, provided the original author and source are credited.

\section{ABSTRACT:}

Activating mutations in KRAS are prevalent in cancer, but therapies targeted to oncogenic RAS have been ineffective to date. These results argue that targeting downstream effectors of RAS will be an alternative route for blocking RAS-driven oncogenic pathways. We and others have shown that oncogenic RAS activates the NF-KB transcription factor pathway and that KRAS-induced lung tumorigenesis is suppressed by expression of a degradation-resistant form of the IKBa inhibitor or by genetic deletion of IKK $\beta$ or the RELA/p65 subunit of NF-KB. Here, genetic and pharmacological approaches were utilized to inactivate IKK in human primary lung epithelial cells transformed by KRAS, as well as KRAS mutant lung cancer cell lines. Administration of the highly specific IKK $\beta$ inhibitor Compound A (CmpdA) led to NF$K B$ inhibition in different KRAS mutant lung cells and siRNA-mediated knockdown of IKKa or IKK $\beta$ reduced activity of the NF-KB canonical pathway. Next, we determined that both IKK $\alpha$ and IKK $\beta$ contribute to oncogenic properties of KRAS mutant lung cells, particularly when p53 activity is disrupted. Based on these results, CmpdA was tested for potential therapeutic intervention in the Kras-induced lung cancer mouse model (LSL-KrasG12D) combined with loss of p53 (LSL-KrasG12D/p53fl/fl). CmpdA treatment was well tolerated and mice treated with this IKK $\beta$ inhibitor presented smaller and lower grade tumors than mice treated with placebo. Additionally, IKK $\beta$ inhibition reduced inflammation and angiogenesis. These results support the concept of targeting IKK as a therapeutic approach for oncogenic RAS-driven tumors with altered p53 activity.

\section{INTRODUCTION}

Lung cancer is the leading cause of cancer-related deaths worldwide [1] and even though novel targeted therapies have been developed that show efficacy for a subset of patients [2,3], for the great majority of lung cancer patients effective targeted therapies are still lacking. This is the case for the $20-50 \%$ of lung cancer patients that harbor activating point mutations in the KRAS GTPase gene [4-6]. Therefore, identification of druggable targets in the KRAS signaling pathway could lead to novel therapeutic alternatives for lung cancer, as well as other RAS-driven cancers.

Constitutive, signal-independent activation of KRAS via mutation is not only associated with poor prognosis and therapy resistance in a variety of cancers, but is sufficient to trigger malignant transformation and drive the oncogenic phenotype $[7,8]$. Therefore, KRAS is a rational target for cancer therapy. Unfortunately, due to the difficulty in effectively inhibiting the biological activity of RAS proteins, approaches to directly target these proteins for therapy have been so far unsuccessful [9]. In this regard, intense efforts are being made to target 
known downstream effectors of RAS $[10,11,12]$. So far this approach has yielded limited therapeutic success, thus reflecting the need to better understand the molecular pathways triggered by oncogenic RAS.

A mechanism that is known to be important for RAS-induced oncogenesis is the activation of the transcription factor $N F-\kappa B$. NF- $\kappa$ B is a ubiquitously expressed transcription factor that is maintained in an inactive form through interactions with the inhibitor of $\kappa B$ (I $\kappa \mathrm{B})$ proteins. Canonical NF- $\kappa \mathrm{B}$ activation downstream of inflammatory cytokines and other inducing molecules is mediated by the I $\mathrm{BB}$ kinase (IKK) complex, which is comprised of a regulatory subunit (NEMO) and two catalytic subunits (IKK $\alpha$ and IKK $\beta$ ). Once activated, the IKK complex phosphorylates $\mathrm{I} \kappa \mathrm{B}$, which leads to its rapid ubiquitination and proteasome-mediated degradation. In this pathway, the p50-p65/RELA heterdodimer is then released and accumulates in the nucleus to regulate target gene transcription [13-17]. In the non-canonical NF- $\kappa \mathrm{B}$ pathway, NIK activates an IKK $\alpha$ homodimer to lead to nuclear accumulation of a p52-RELB heterodimer $[13,14,16,17]$. Additionally, IKKe and TBK1, IKKrelated kinases can activate p65- and c-REL-containing complexes [18,19].

We previously demonstrated that NF- $\kappa \mathrm{B}$ is activated downstream of oncogenic RAS and that inhibition of NF$\kappa \mathrm{B}$ leads to RAS-induced cell death [20,21]. Inhibition of $\mathrm{NF}-\kappa \mathrm{B}$ by expression of the super-repressor form of $\mathrm{I} \kappa \mathrm{B} \alpha$ [22] or deletion of the RELA/p65 subunit of NF- $\kappa B$ [23] blocks KRAS-induced lung tumors. In that latter work, we demonstrated that KRAS activates the transcription factor NF- $\kappa$ B in lung tumors in situ and that loss of p65 in the tumors leads to the induction of apoptosis [23]. Barbie et al [24] have shown that the IKK-related kinase TBK1 is important as a survival factor in KRAS-driven cancer cells, potentially through a mechanism that involves c-REL. Duran et al [25] demonstrated that oncogenic KRAS can activate IKK through the signaling adaptor p62 and other studies have shown that genetic deletion of IKK $\beta$ in different cancer models suppresses RAS-induced tumorigenesis [26-28].

Here we show that pharmacological inhibition of IKK $\beta$ in primary human lung epithelial cells transformed by KRAS, as well as KRAS mutant lung cancer cell lines, inhibits NF- $\kappa B$ activity and reduces cell growth. Further analysis indicated that this response was at the level of cellular proliferation and not induction of cell death. Genetic targeting of KRAS, IKK $\beta$ or IKK $\alpha$ by siRNA had similar effects on NF- $\kappa \mathrm{B}$ activity, reducing canonical NF$\kappa \mathrm{B}$ activation. In addition, cell growth and proliferation were also similarly affected. Nonetheless, even though $\mathrm{NF}-\kappa \mathrm{B}$ activity was reduced in all cells examined, reduced cell growth was restricted to cells with lost or disrupted p53 function. Therefore, we treated a KRAS-induced lung cancer mouse model combined with loss of the tumor suppressor p53 with a highly specific IKK $\beta$ inhibitor
(Compound A, Bayer [29]). The inhibitor is well tolerated and lowers tumor burden and tumor grade. Consistent with the cell-based studies, Compound A (CmpdA) treatment reduces tumor proliferation. CmpdA also affects the tumor microenvironment, reducing the tumorassociated macrophage footprint along with reduced intratumoral vasculature. These results show that IKK $\alpha$ or IKK $\beta$ inhibition reduces lung cancer cell proliferation in vitro and pharmacological IKK $\beta$ targeting reduces lung cancer growth in vivo, supporting the hypothesis that IKK inhibition therapy will have clinical benefits in lung cancer as well as other cancers, particularly for patients with KRAS mutations and altered p53 activity.

\section{RESULTS}

\section{IKK targeting decreases canonical NF- $\kappa \mathrm{B}$ activity in KRAS mutant cell lines}

We had previously shown that oncogenic KRAS expression in low-passage primary immortalized human small airway cells correlates with increased

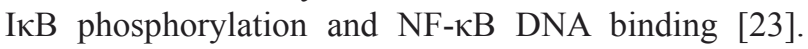
In addition, IKK inhibition with $\mathrm{CmpdA}$ reduced NF$\kappa \mathrm{B}$ DNA binding activity in these genetically defined cells [23]. To further address the contribution of IKK to oncogenic RAS-driven NF- $\mathrm{BB}$ activity, human as well as mouse lung cancer cell lines harboring oncogenic KRAS were transfected with an NF- $\mathrm{B}$-dependent luciferase reporter and treated with CmpdA. In each experiment, the IKK inhibitor reduced $N F-\kappa B$ reporter activity (Fig. 1A). CmpdA also blocked phosphorylation of IKK $\beta$ substrates I $\mathrm{B} \alpha$ or p65 in these cell lines (Fig. $1 \mathrm{~B})$. Furthermore, when KRAS or IKK $\beta$ expression was reduced by transfecting human lung cancer cell lines with siRNA targeting either KRAS or IKK $\beta$, NF- $\kappa$ B luciferase reporter activity was also inhibited, indicating that, in these cells, both KRAS and IKK $\beta$ are promoting NF- $\kappa \mathrm{B}$ activity (Supplementary Fig. S1).

Based on the results showing IKK $\beta$ is involved in KRAS-induced NF- $\kappa B$ activation, and based on published evidence that NF- $\kappa \mathrm{B}$ activation by KRAS in lung cells involves the IKK complex [23,25], we hypothesized that in human lung cells KRAS utilizes the canonical pathway to activate NF- $\mathrm{BB}$. In this regard, we questioned whether siRNA-mediated inhibition of IKK $\alpha$ would also affect NF- $\kappa \mathrm{B}$ activity in $K R A S$ mutant lung cells. IKK $\alpha$ is typically considered to be less important in canonical $\mathrm{NF}-\kappa \mathrm{B}$ signaling as compared to IKK $\beta$ [30]. Interestingly, knockdown of IKK $\alpha$ in the lung cancer cells studied not only reduced NF- $\kappa$ B activity (Supplementary Fig. S1), but more importantly, inhibition of KRAS, IKK $\beta$ or IKK $\alpha$ by siRNA in $\mathrm{H} 358$ cells inhibited $\mathrm{I} \kappa \mathrm{B} \alpha$ phosphorylation and degradation, a hallmark of the canonical NF- $\kappa \mathrm{B}$ activation 
pathway (Fig. 1C).

\section{IKK targeting reduces proliferation of KRAS positive cells dependent on the loss of $\mathrm{p53}$ function}

Next, we examined the effects of CmpdA treatment on growth of several KRAS positive cells. Interestingly, in spite of reducing NF- $\mathrm{KB}$ activity in all cell lines studied, CmpdA did not affect cell growth uniformly. SAKRAS cells are very sensitive to CmpdA treatment, whereas their isogenic cells lacking oncogenic KRAS (SALEB) are less sensitive (Fig. 2A), indicating that the effect of CmpdA on cell growth is dependent on KRAS status. In order to further assess this dependency, we used H1703 lung adenocarcinoma cells, which harbor wild-type KRAS, to generate HA-tagged $\mathrm{KRAS}^{\mathrm{G} 12 \mathrm{~V}}$-inducible $\mathrm{H} 1703$ human lung cancer cells. We observed that induction of KRAS $^{\mathrm{G} 12 \mathrm{~V}}$ expression with doxycycline in $\mathrm{H} 1703$ cells leads to increased I $\mathrm{B} \alpha \boldsymbol{\alpha}$ phosphorylation and to increased NF- $\kappa$ B reporter activity (Figs. $2 \mathrm{~B}$ and $2 \mathrm{C}$ ). These effects on NF- $\kappa \mathrm{B}$ activity were not observed in doxycyclinetreated empty vector control cells (H1703-TrexB cells), which do not express $\operatorname{KRAS}^{\mathrm{G} 12 \mathrm{~V}}$ (Figs. 2B and 2C). $\mathrm{CmpdA}$ treatment blocked IкB $\alpha$ phosphorylation in both KRAS $^{\text {G12V }}$ and TrexB H1703 cells (Fig. 2B). We then used this cell line model to evaluate CmpdA sensitivity. Induction of $\mathrm{KRAS}^{\mathrm{G} 12 \mathrm{~V}}$ expression with doxycycline in H1703 cells leads to enhanced cell growth, which is blocked by treatment with CmpdA (Fig. 2D). CmpdA had no effect on growth of H1703 TrexB cells, which do not express $\mathrm{KRAS}^{\mathrm{G} 12 \mathrm{~V}}$ upon doxycycline administration (Fig. 2D).

CmpdA sensitivity was also dependent on the status

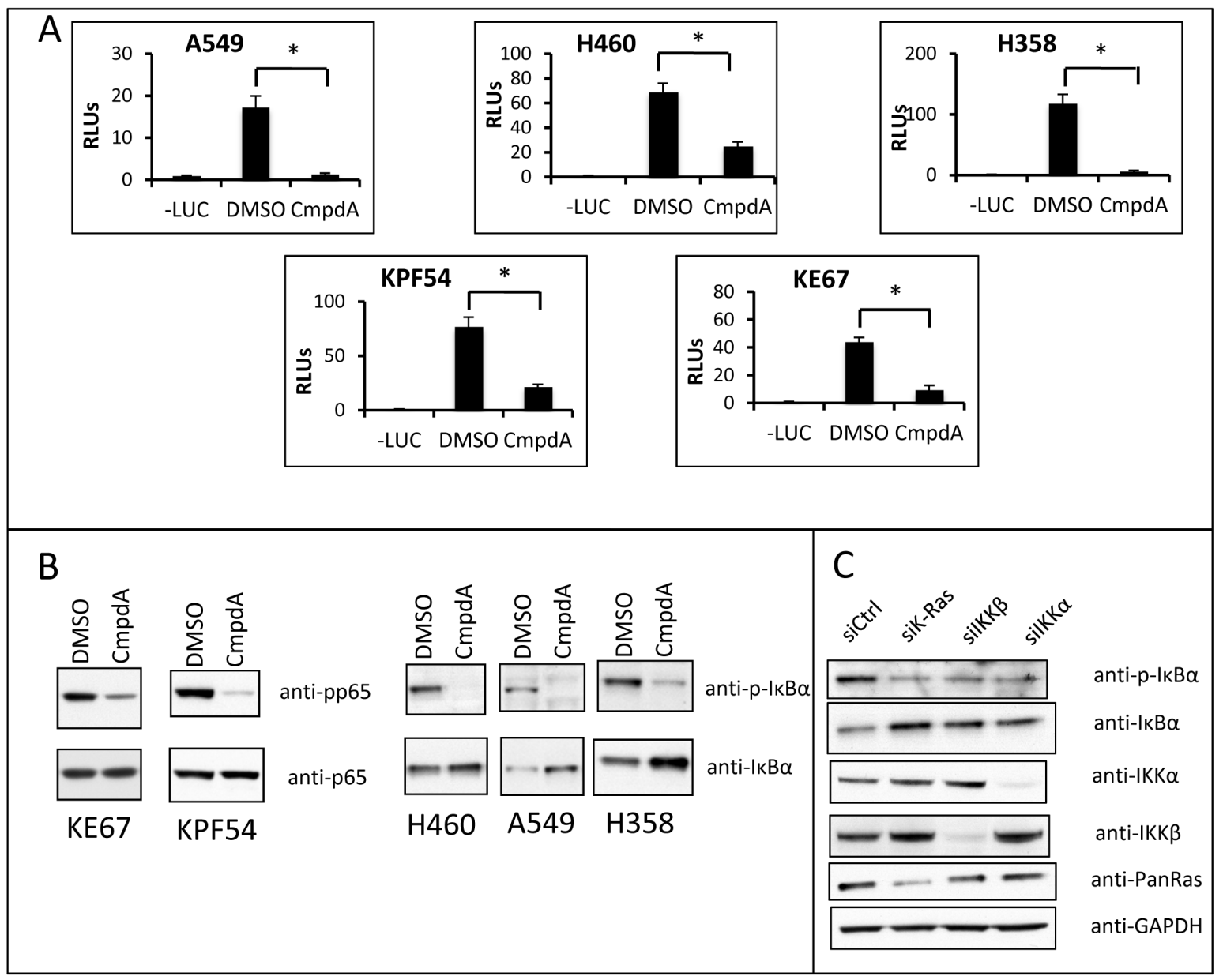

Fig 1: Targeting IKK $\boldsymbol{\beta}$ reduces NF-кB activity in KRAS positive lung cells. A) The indicated cell lines were transfected with $100 \eta \mathrm{g}$ of an NF- $\kappa$ B-responsive firefly luciferase reporter vector $(3 \mathrm{x}-\kappa \mathrm{B}-\mathrm{Luc})$ and $5 \eta \mathrm{g}$ of Renilla luciferase vector (pRL-TK) and either treated with $0.1 \%$ DMSO or $5 \mu \mathrm{M}$ CmpdA for $16 \mathrm{~h}$.-LUC) negative control (cells transfected with pcDNA3 instead of $3 \mathrm{x}-\mathrm{kB}-\mathrm{Luc}$ and pRL-TK); RLUs) Relative luciferase units. B) The indicated cell lines were treated with $0.1 \%$ DMSO or $5 \mu \mathrm{M}$ CmpdA for 30 min and protein lysates were analyzed for NF- $\mathrm{BB}$ activity by Western Blotting. Antibodies used are indicated. C) H358 cells were transfected with the indicated siRNAs as described in methods and analyzed for NF- $\kappa$ B activity at $72 \mathrm{~h}$ by Western Blotting. Antibodies used are indicated. Statistical significance was measured when appropriate by Student's $t$-test $\left({ }^{*} \mathrm{p}<0.05\right)$ when compared to experimental control samples (DMSO). Error bars represent average \pm 1 s.d. 
of the tumor suppressor p53. KRAS positive cell lines with wild-type (WT) p53 (A549 and H460) were less sensitive to CmpdA treatment than KRAS positive p53 null (H358) or p53 mutant (H1792) cell lines (Fig. 3A). In order to address a role for p53 in the sensitivity to IKK inhibition, we analyzed cells isolated from KRAS-induced lung cancer mouse models with WT p53 (KE67) and with deletion of the p53 gene (KPF54). Results demonstrate that the tumor cells with loss of p53 are more sensitive to IKK $\beta$ inhibition than cells with WT p53 (Fig. 3A).

Because loss of p53 can increase IKK $\beta$ activity [31] and has been shown to activate NF- $\kappa B$ in KRAStransformed lung tumor cells [22], we propose that, even though NF- $\mathrm{NB}$ is active in all KRAS positive cell lines, loss or disruption of p53 activity would to lead to enhanced IKK $\beta$ activation and thus to enhanced CmpdA sensitivity (see discussion). In order to determine if p53 null cells have higher NF- $\mathrm{KB}$ activity than p53 WT cells, we performed luciferase reporter assays on murine cells derived from KRAS-induced lung tumors with either WT p53 or with loss of p53. As can be seen in Fig. 3B, KPF54 cells, which lack p53, display higher NF-кB reporter activity than KE67 cells, which express WT p53. Similar results were observed when we compared NF- $\kappa B$ activity between human cells with different p53 status. A549 cells, which express WT p53 have lower levels

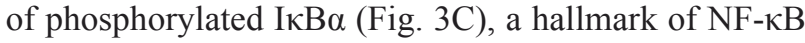
activation. Finally, we expressed p53 in human H358

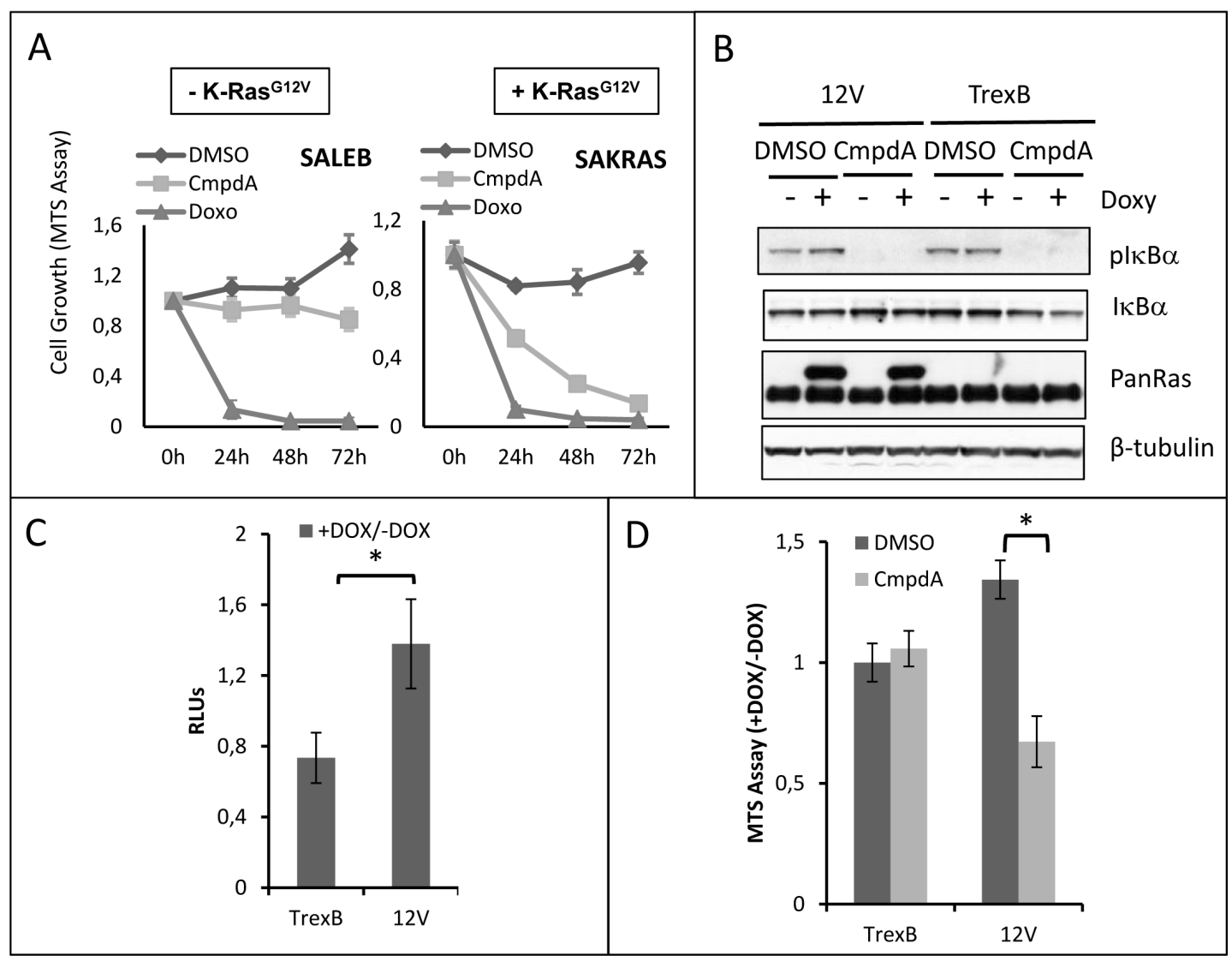

Fig 2: CmpdA reduces growth of lung cells in a KRAS dependent manner. A) Primary immortalized human airway cells (SALEB) and their KRAS-transformed counterpart (SAKRAS) were treated with $0.1 \%$ DMSO or $5 \mu \mathrm{M}$ CmpdA for the indicated timepoints. $2 \mu \mathrm{g} / \mathrm{mL}$ Doxorubicin (Doxo) was used as a positive control. Cell growth was measured using a colorimetric MTS tetrazolium assay (CellTiter 96® $\mathrm{AQ}_{\text {ueous }}$ One Solution Cell Proliferation Assay from Promega, Madison, WI). B) H1703-TrexB and H1703-G12V lung cancer cells were treated with $2 \mu \mathrm{g} / \mathrm{mL}$ doxycycline (Doxy) for $24 \mathrm{~h}$ where indicated to induce KRAS expression. Subsequently cells were treated with $0.1 \%$ DMSO or $5 \mu \mathrm{M} \mathrm{CmpdA}$ for 30 min and analyzed for NF- $\kappa \mathrm{B}$ activity by Western Blotting. Antibodies used are indicated. C) H1703-TrexB and H1703-G12V cells were transfected with 100ng of an NF-kB-responsive firefly luciferase reporter vector (3x-kBLuc) and $5 \eta \mathrm{g}$ of Renilla luciferase vector (pRL-TK). Cells were induced with $2 \mu \mathrm{g} / \mathrm{mL}$ doxycycline (+DOX) or left untreated (-DOX) for $24 \mathrm{~h}$ and subsequently treated for $16 \mathrm{~h}$ with either $0.1 \%$ DMSO or $5 \mu \mathrm{M}$ CmpdA as indicated. Results are expressed as the luciferase activity ratio of induced/uninduced cells (+DOX/-DOX). RLUs) Relative luciferase units. D) H1703-TrexB and H1703-G12V cells were treated with $2 \mu \mathrm{g} / \mathrm{mL}$ Doxycycline (+DOX) for $24 \mathrm{~h}$ to induce KRAS expression. Control cells were left untreated (-DOX). Subsequently, they were treated either with $0.1 \%$ DMSO or $5 \mu \mathrm{M} \mathrm{CmpdA}$ and cell growth was measured $48 \mathrm{~h}$ later using a colorimetric MTS tetrazolium assay (CellTiter $96 \AA \mathrm{AQ}_{\text {ueous }}$ One Solution Cell Proliferation Assay from Promega, Madison, WI). Results are expressed as growth ratio of induced/uninduced cells (+DOX/-DOX). Statistical significance in all cases was measured by Student's $t$-test $(* \mathrm{p}<0.05)$ when compared to experimental control samples (DMSO). Error bars represent average \pm 1 s.d. 


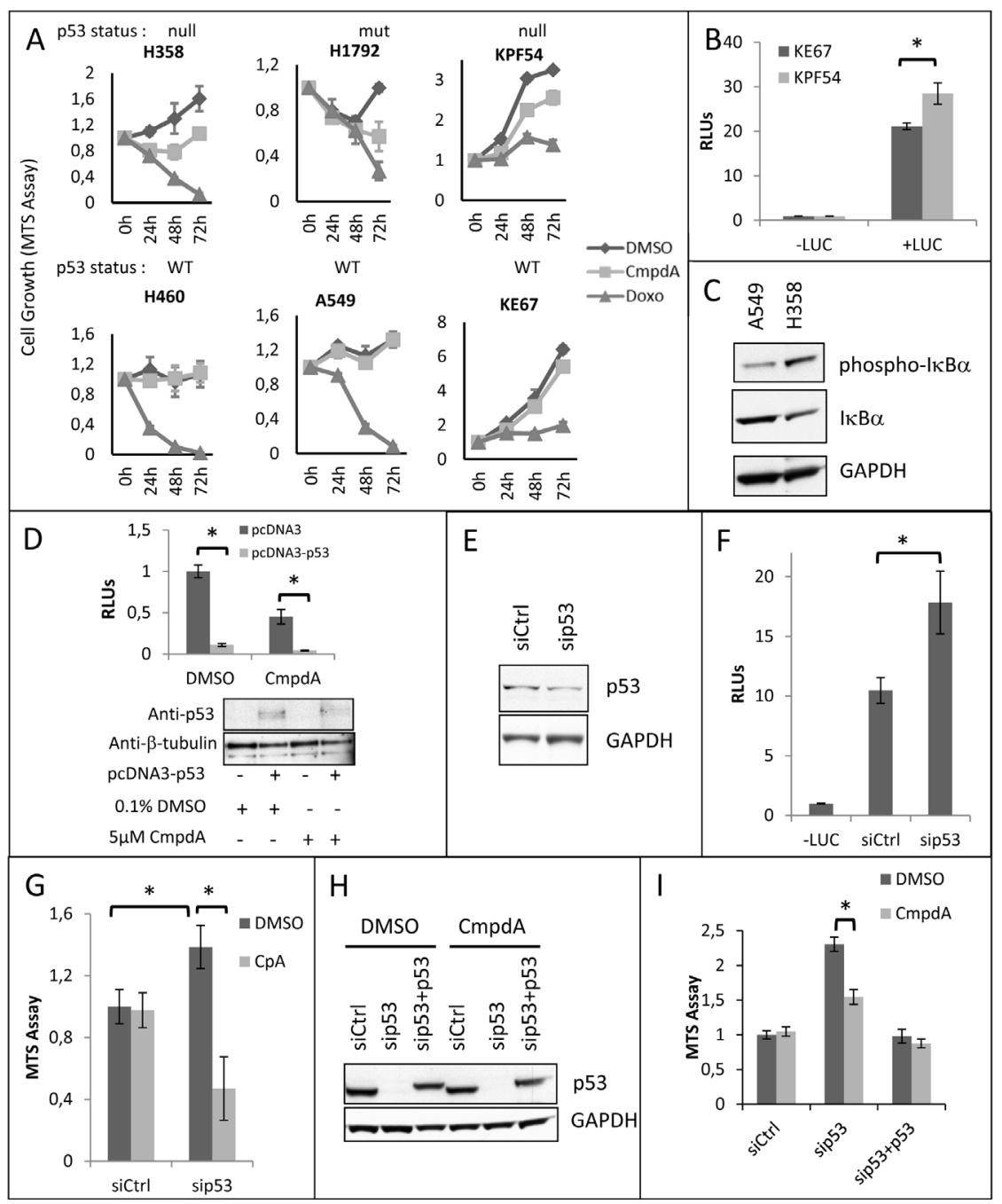

Fig 3: CmpdA reduced growth of KRAS positive lung cancer cells depends on loss or mutation of p53. A) Human and mouse KRAS positive lung cancer cell lines harboring wildtype (WT) p53 (A549, H460, KE67), mutant p53 (H1792) or lacking (null) p53 (H358, KPF54) were treated with either $0.1 \%$ DMSO or $5 \mu \mathrm{M}$ CmpdA as indicated. $2 \mu \mathrm{g} / \mathrm{mL}$ Doxorubicin (Doxo) was used as a positive control. Cell growth was measured at the indicated timepoints using a colorimetric MTS tetrazolium assay (CellTiter $96 \circledR \mathrm{AQ}_{\text {ueous }}$ One Solution Cell Proliferation Assay from Promega, Madison, WI). B) p53 WT KE67 and p53 null KPF54 cell lines were transfected with

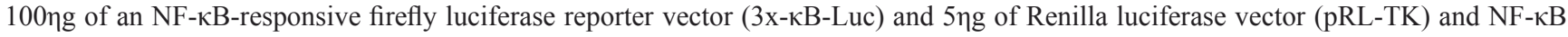
activity was analyzed by dual luciferase reporter assays. -LUC) negative control (cells transfected with pcDNA3 instead of 3x-kB-Luc and pRL-TK); RLUs) Relative luciferase units. C) H358 and A549 cells were analyzed for NF-kB activity by Western Blotting. Antibodies used are indicated. D) p53 null $\mathrm{H} 358$ cells were transfected with 100 $\mathrm{ng}$ of an NF-kB-responsive firefly luciferase reporter vector (3x-kB-Luc),

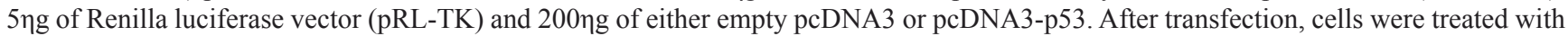
either $0.1 \%$ DMSO or $5 \mu \mathrm{M}$ CmpdA for $16 \mathrm{~h}$. NF-kB activity was analyzed by dual luciferase reporter assays. Expression of recombinant p53 was evaluated by Western Blotting. Antibodies used are indicated. RLUs) Relative luciferase units. E) p53 WT murine KE67 cells were transfected as described in methods with a siRNA targeting murine p53 (sip53) or non-targeting siRNA (NTctrl). At 48h these cells

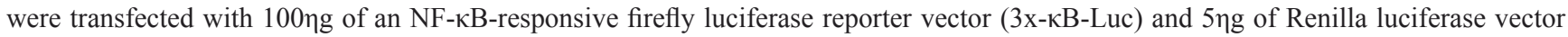
(pRL-TK) and analyzed at 72h after siRNA transfection for knockdown efficiency by Western Blotting. Antibodies used are indicated. F) KE67 cells were transfected as described in (E) and NF- $\mathrm{kB}$ activity was analyzed by dual luciferase reporter assays. - LUC) negative control (cells transfected with pcDNA3 instead of 3x-kB-Luc and pRL-TK); RLUs) Relative luciferase units. G) KE67 cells were transfected as described in methods with a siRNA targeting murine p53 (sip53) or non-targeting siRNA (NTctrl). Subsequently cell growth was measured at $72 \mathrm{~h}$ post-transfection using a colorimetric MTS tetrazolium assay (CellTiter $96 \AA \mathrm{AQ}_{\text {ueous }}$ One Solution Cell Proliferation Assay from Promega, Madison, WI). H) A549 cells were transfected as described in methods with a siRNA smartpool targeting human p53 (sip53) or a non-targeting siRNA (NTctrl). Subsequently, cells transfected with sip53 were transfected either with pcDNA3 (empty vector control) or with pcDNA3-p53 vector. Analysis of p53 knockdown and p53 re-expression was performed by Western Blotting. Antibodies used are indicated. I) A549 cells were transfected as described in $\mathrm{H}$ and cell growth was evaluated at $72 \mathrm{~h}$ post-transfection using a colorimetric MTS tetrazolium assay (CellTiter $96 \circledR \mathrm{AQ}_{\text {ueous }}$ One Solution Cell Proliferation Assay from Promega, Madison, WI). Statistical significance in all cases was measured by Student's $t$-test $(* \mathrm{p}<0.05)$ when compared to experimental control samples (siCtrl). Error bars represent average \pm 1s.d. 
cells, which are p53 null, and this resulted in reduced NF$\kappa \mathrm{B}$ reporter activity (Fig. 3D).

In order to determine if the increased sensitivity to CmpdA displayed by p53 null cell lines can be caused by loss of p53, we used RNA interference to reduce p53 expression in p53 WT KE67 murine cells and in p53 WT A549 human cells. A 58\% reduction in p53 expression in KE67 cells (Fig. 3E) results, not only in increased NF$\kappa \mathrm{B}$ reporter activity (Fig. $3 \mathrm{~F}$ ), but also in increased cell growth, which is reduced by CmpdA treatment (Fig.

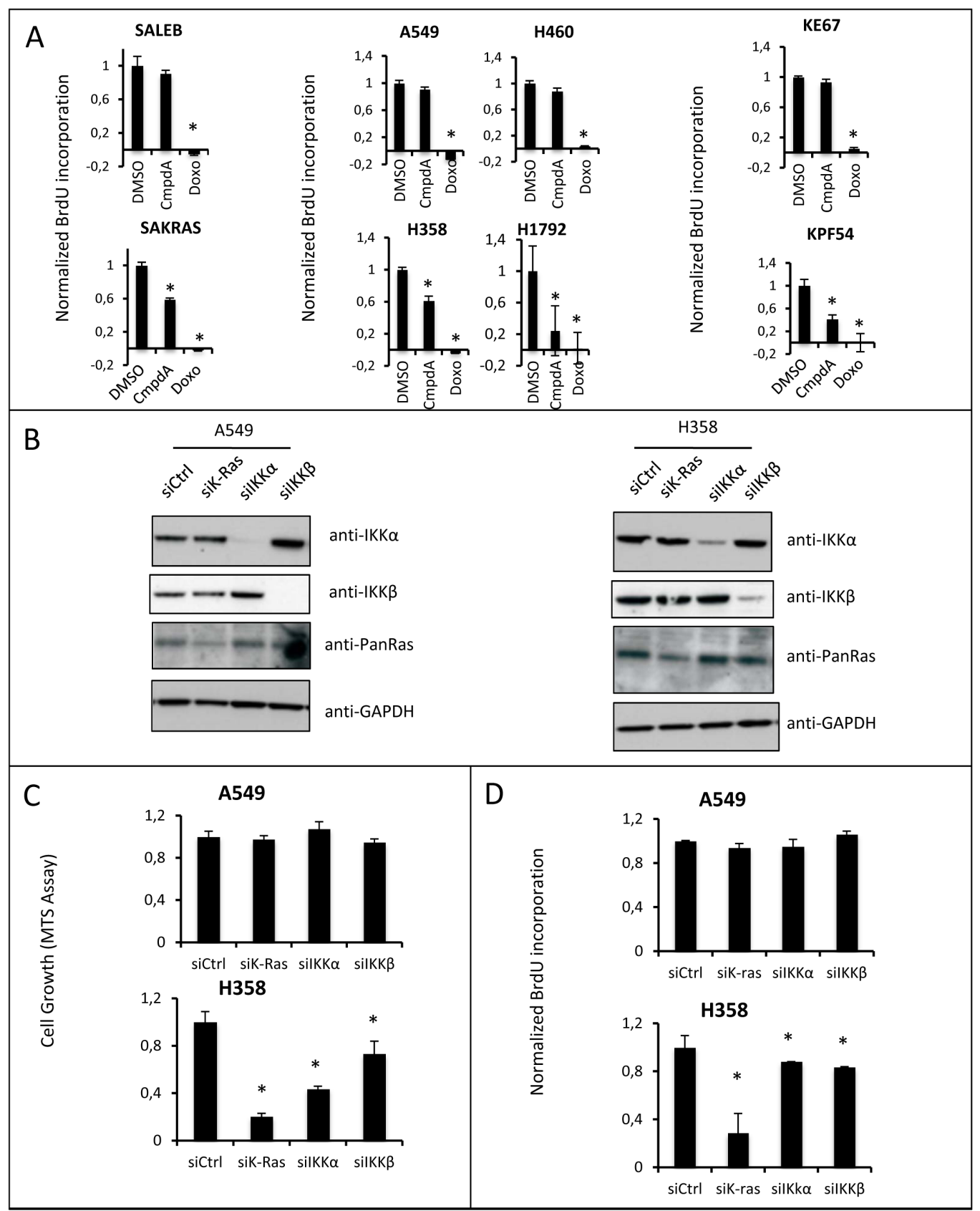

Fig 4: IKK targeting reduces lung cell growth by inhibiting cell proliferation. A) Proliferation was evaluated by BrdU incorporation to measure DNA synthesis in a colorimetric assay (BrdU Cell Proliferation Assay from EMD Millipore, Billerica, MA) in all indicated cell lines after $0.1 \%$ DMSO or $5 \mu \mathrm{M}$ CmpdA treatment for $48 \mathrm{~h}$. $2 \mu \mathrm{g} / \mathrm{mL}$ Doxorubicin (Doxo) was used as a positive control. B) The indicated cell lines were transfected as described in methods with a non-targeting control siRNA (siCtrl) or with siRNA smartpools targeting KRAS ( $\operatorname{si} K R A S), \operatorname{IKK} \beta(\operatorname{si} I K K \beta)$ or IKK $\alpha(\operatorname{si} I K K \alpha)$ and efficacy of siRNA targeting was evaluated at $72 \mathrm{~h}$ by Western Blotting with the indicated antibodies. C) Cell growth of siRNA-transfected cells (as in B) was measured using a colorimetric MTS tetrazolium assay (CellTiter 96® $\mathrm{AQ}_{\text {ueous }}$ One Solution Cell Proliferation Assay from Promega, Madison, WI); D) Proliferation of siRNA transfected cells (as in B) was evaluated at 72h by BrdU incorporation to measure DNA synthesis (BrdU Cell Proliferation Assay from EMD Millipore, Billerica, MA). Statistical significance in all cases was measured by Student's $t$-test $\left({ }^{*} \mathrm{p}<0.05\right)$ when compared to experimental control samples (DMSO). Error bars represent average \pm 1 s.d. 
3G). Interestingly CmpdA had no effect on KE67 cells transfected with a control small interfering RNA (siRNA). Similar results were observed in A549 cells. Inhibition of p53 expression resulted in increased A549 cell growth and rendered A549 cells sensitive to CmpdA treatment (Figs. 3H and 3I). More importantly, p53 re-expression in these cells, not only reduced cell growth, but turned them insensitive to IKK $\beta$ inhibition (Figs. $3 \mathrm{H}$ and 3I). In order to further corroborate this data we used HCT116 colon cancer cells that harbor oncogenic KRAS and that have been engineered by homologous recombination to lose the p53 gene, making it straightforward to evaluate the effect of p53 loss in an isogenic setting. Not only is NF- $\mathrm{kB}$ activity higher in HCT116-p53 knockout (KO) cells than in HCT116-p53 WT cells (Supplementary Fig. S2A and S2B), but also, as assessed by MTT assays, HCT116-p53 WT cells are insensitive to CmpdA treatment, whereas HCT116-p53 KO cells are sensitive (Supplementary Fig. S2C). When we used clonogenic cell growth assays, both cell lines were sensitive to CmpdA treatment, but they displayed different levels of sensitivity. Whereas HCT166-p53 WT cells showed a 55\% reduction in colony formation, HCT116-p53 KO cells showed an 80\% reduction (Supplementary Fig. S2D). Taken together these results indicate that the status of both KRAS and the p53 tumor suppressor are important in determining sensitivity to IKK $\beta$ inhibition therapy.

In order to determine the mechanism leading to reduced cell growth induced by CmpdA, we analyzed both apoptosis and reduced proliferation. Interestingly, even though NF- $\mathrm{KB}$ is known as an antiapoptotic transcription factor, growth reduction was not caused by apoptotic cell death, as CmpdA failed to induce apoptosis in any of the cell lines (Supplementary Fig. S3A). However, reduction in cell growth in all sensitive cell lines was associated with reduced proliferation as measured by $\mathrm{BrdU}$ incorporation (Fig. 4A).

In order to validate IKK $\beta$ as the relevant CmpdA target in mediating reduced proliferation, we pursued siRNA experiments in H358 cells and A549 cells (Fig. 4B). The A549 cell line, which is resistant to CmpdA treatment, is also resistant to alterations in cell growth (Fig. 4C) and proliferation (Fig. 4D) upon IKK $\beta$ knockdown. On the other hand the H358 cell line, which is sensitive to CmpdA treatment, is more sensitive to loss of IKK $\beta$ by siRNA, displaying a $27 \%$ reduction in cell growth (Fig. 4C) and $20 \%$ in proliferation (Fig. 4D). The reduction in proliferation observed upon IKK $\beta$ knockdown is not as robust as that attained with CmpdA treatment ( $20 \%$ versus $39 \%$ ). This could be caused by residual expression of IKK $\beta$ in the knockdown experiments and/or a compensatory increase in IKK $\alpha$ activation, which could affect cell proliferation (see below). siRNA-mediated knockdown of KRAS in H358 cells led to a greater reduction of cell growth (Figs. 4C and 4D), suggesting that KRAS activates additional pathways that contribute to cell proliferation.

Because IKK $\alpha$ is a member of the IKK complex and because siRNA targeting of IKK $\alpha$ in KRAS positive cells also reduces NF- $\kappa B$ activity and inhibits $I \kappa B \alpha$ phosphorylation/degradation (Supplementary Fig. S1 and Fig. 1C), it is important to determine the contribution of this kinase to the proliferative phenotype of KRAS positive/p53 null lung cancer cells. Therefore, we determined if siRNA knockdown of IKK $\alpha$ would affect cell growth, apoptosis and proliferation. Interestingly, like inhibition of IKK $\beta$, siRNA to IKK $\alpha$ in p53 WT A549 cells did not affect cell growth or proliferation, whereas in the CmpdA sensitive H358 cell line knockdown of IKK $\alpha$ also decreases cell growth and proliferation (Fig. 4C and 4D), suggesting that both IKK $\alpha$ and IKK $\beta$ contribute to promote cell proliferation. Again, consistent with the observed lack of effect of CmpdA on apoptosis, knockdown of IKK $\alpha$, IKK $\beta$ or even KRAS in these cell lines, did not trigger apoptosis (Supplementary Fig. S3B).

To further corroborate these results, we examined a panel of apoptosis and proliferation-related genes in H358 cells following knockdown of KRAS, IKK $\alpha$ or IKK $\beta$. Whereas, no significant changes were observed in the expression of anti-apoptotic genes $B C L 2$ and $C I A P 2$, expression of the proliferation-related genes $E 2 F 1$ and $M Y C$ were affected (Supplementary Fig. S3C). Knockdown of KRAS inhibited expression of both E2F1 and $M Y C$. Interestingly, even though to a lesser extent, knockdown of either IKK $\alpha$ or IKK $\beta$ also inhibited $E 2 F 1$ expression. In the case of $M Y C$, knockdown of IKK $\alpha$ or IKK $\beta$ also reduced $M Y C$ expression to the same extent as knockdown of KRAS. Taken together, these results indicate that both IKK forms induce NF-KB activity and proliferation downstream of RAS.

\section{In vivo administration of $\mathrm{CmpdA}$ reduces tumor burden in a mouse model of lung cancer triggered by KRAS activation coupled with p53 loss.}

Given that CmpdA could decrease cell growth and proliferation of different cell lines with oncogenic $K R A S$ mutations and loss or disruption of p53, we decided to test in a preclinical mouse model if this inhibitor would have similar effects in vivo. For that purpose, we used oncogenic KRAS inducible Lox-Stop-Lox ( $L S L)$ $\mathrm{Kras}^{\mathrm{G}}{ }^{12 \mathrm{D}}$ mice with conditional inactivation of p53 [32]. In this model, both expression of oncogenic $\mathrm{KRAS}^{\mathrm{G} 12 \mathrm{D}}$ and inactivation of p53 are triggered by Cre-mediated recombination. Lung tumors were induced in this model by intranasal administration of Cre-expressing adenovirus (AdCre) as previously described [32]. Infected mice will

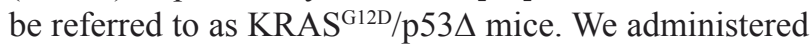
CmpdA or placebo beginning at 8 weeks post-infection (when lung tumors are already present) for 4 weeks daily. CmpdA was well tolerated both in the tumor bearing 


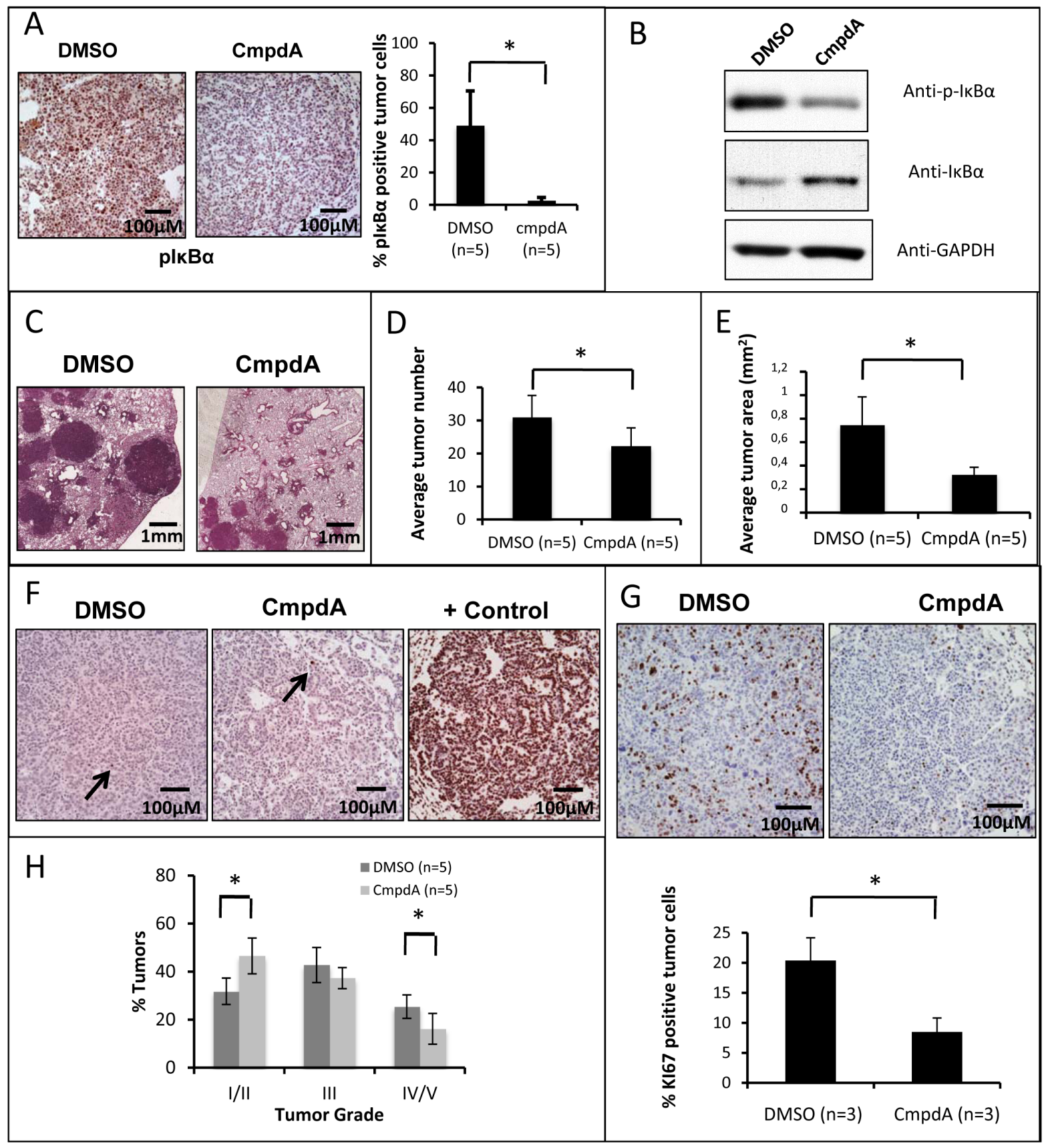

Fig 5: Targeting IKK $\beta$ in the KRASG12D/p53 $\Delta$ conditional mouse lung tumor model reduces tumor burden in vivo.

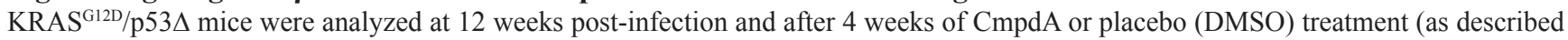
in methods). A) Immunohistochemistry for phospho-IкB $\alpha$ (positive cells are brown). A representative picture of stained lung tumor slides of CmpdA-treated and placebo-treated lungs is displayed on the left panel. The graph on the right panel is a quantitative representation of the data. B) Western Blotting analysis of I $\mathrm{KB} \alpha$ phosphorylation/degradation of CmpdA-treated and placebo-treated lung tumors. Antibodies used are indicated. C) A representative picture of Hematoxylin/Eosin (H/E) stained lung slides of CmpdA-treated and placebo-treated lungs. D) Number of KRAS-induced neoplastic lesions was determined by counting lesions in $\mathrm{H} / \mathrm{E}$ stained lung sections as described in methods. E) Average tumor area was determined by measuring tumor area using ImageJ software. F) TUNEL positive cells (brown) were stained according to the Apoptag Plus In Situ Apoptosis Detection Kit (EMD Millipore, Billerica, MA). A representative picture of stained lung slides of CmpdA-treated and placebo-treated lungs is displayed (rare positive cells are indicated by arrows). A DNase treated slide was used as a positive control (+ control). G) Immunohistochemistry for KI67 (positive cells are brown). A representative picture of stained lung slides of CmpdA-treated and placebo-treated lungs is displayed on the top panel. The graph on the bottom panel is a quantitative representation of the data. H) Analysis of lung tumor grade was performed on $\mathrm{H} / \mathrm{E}$ stained lung sections as described in methods. Statistical significance in all cases was measured by Student's $t$-test $\left({ }^{*} \mathrm{p}<0.05\right)$ when compared to experimental control samples (DMSO). Error bars represent average \pm 1s.d. 
animals as well as in healthy controls. At the endpoint, the animals were euthanized, and the tumors of CmpdAtreated animals were compared to the tumors of placebotreated animals. To assess IKK $\beta$ inhibition in the tumors, we performed phospho-I $\kappa \mathrm{B} \alpha$ immunohistochemistry. Consistent with an inhibitory effect on IKK, tumors of CmpdA-treated animals have a dramatically reduced percentage of phospho-I $\kappa \mathrm{B} \alpha$ positive tumor cells (Fig. $5 \mathrm{~A})$. Decreased $\mathrm{I} \kappa \mathrm{B} \alpha$ phosphorylation was confirmed by western blotting, as well as increased levels of total $\mathrm{I} \kappa \mathrm{B} \alpha$ (Fig. 5B), consistent with reduced IKK activity. Even though tumors were still present at the end of treatment, CmpdA-treated animals exhibited significantly decreased tumor burden (Fig. 5C-E). We observed, not only a small (but significant) decrease in tumor number (Fig. 5D), but also a significant decrease in average tumor area (Fig. 5C and E). Taken together these results indicate that CmpdA can reduce KRAS-induced lung tumor growth in a p53 null context.

In order to determine if this reduction in tumor growth was due to tumor cell apoptosis or reduced tumor cell proliferation, we performed TUNEL staining of lung slides, as well as KI67 staining. Consistent with our cell-based experiments, we saw no change in apoptotic cells between CmpdA and DMSO treated animals (Fig. $5 F)$. In fact, most tumors were TUNEL negative. On the other hand KI67 staining was markedly reduced in CmpdA-treated animals (Fig. 5G), indicating that CmpdA reduces lung tumor proliferation. In addition to slowing tumor growth, CmpdA also slows tumor progression. A histopathological analysis revealed that CmpdA treated mice display a higher percentage of grade I/II tumors and lower percentages of grade IV/V tumors (Fig. $5 \mathrm{H}$ ).

Interestingly, the reduction in proliferative index and tumor area in mouse lung tumors treated with CmpdA was much more pronounced than the loss of growth and proliferation inhibition seen in our cell-based experiments, which led us to hypothesize that the effect of CmpdA on tumor burden might not be exclusively tumorintrinsic. In fact, $\mathrm{NF}-\kappa \mathrm{B}$ is an important transcription factor driving inflammation and CmpdA has shown anti-inflammatory properties in a previous study [33]. Because inflammatory cells are important components of the tumor microenvironment, which can cooperate with cancer cells to promote oncogenesis [34], we investigated whether CmpdA would affect the number of inflammatory cells in the lungs of mice treated with CmpdA. Indeed, CmpdA treatment reduces the number of F4/80-positive macrophages in tumor-bearing lungs (Supplementary Fig. S4A).

Previous studies targeting IKK $\beta$ in tumor models did not address the role of IKK $\beta$ inhibition on tumor angiogenesis. Because RAS can promote tumor angiogenesis through the induction of the IL-8 cytokine [35], and because IL- 8 is upregulated by KRAS in an IKK $\beta$-dependent manner [23], we hypothesized that
CmpdA would inhibit tumor angiogenesis. We, therefore, used immunohistochemistry for a specific endothelial marker (CD31) to compare tumor vessel density in CmpdA-treated versus placebo-treated animals. As can be seen in Supplementary Fig. S4B, CmpdA treatment reduces tumor vessel density. These results indicate that this inhibitor affects not only tumor cells, but also the tumor microenvironment, which is an important variable to be considered for therapy design.

Taken together these results suggest that CmpdA or other highly specific IKK $\beta$ or IKK $\alpha$ inhibitors might produce a clinical benefit for patients with KRAS-induced lung cancer with disrupted p53 function.

\section{DISCUSSION}

KRAS-induced cancers are very common, yet despite intense efforts, effective therapies for these malignancies are sofar unavailable. Approaches to target KRAS directly have sofar been unsuccessful [7] and indirect targeting of KRAS through its downstream effectors has proven to be challenging, as KRAS regulates many pathways that impinge on the oncogenic phenotype. Effective KRAS targeting will likely involve combined inhibition of these pathways. Therefore, a better understanding of the oncogenic pathways triggered by KRAS is warranted, as it will identify additional druggable targets that will increase the possibilities for combined therapy design.

To more fully understand the oncogenic pathways triggered by KRAS, we and others have shown that oncogenic KRAS activates NF- $\kappa \mathrm{B}$ in lung tumors, which in turn potentiates lung tumorigenesis. We have shown that KRAS activates an NF- $\kappa \mathrm{B}$ EGFP reporter in lung tumors in situ [23]. In addition, loss of the main NF- $\kappa B$ subunit p65 in KRAS-lung tumors was associated with a reduction in tumor number, spread and grade [23]. Meylan et al [22] have shown the expression of a degradationresistant form of the NF- $\kappa \mathrm{B}$ inhibitor $\mathrm{I} \kappa \mathrm{B} \alpha$, also led to reduced KRAS-induced lung tumor growth. Barbie et al [24] have shown in a variety of different cell line models, that loss of c-REL, another member of the NF- $\mathrm{B}$ family, was synthetically lethal with oncogenic KRAS. Finally, we had originally shown that the combined loss of c-REL and p65 reduced RAS-induced colony formation more than loss of p65 alone [36]. These findings indicate that activation of NF- $\kappa \mathrm{B}$ by KRAS is an important event in tumorigenesis, and that targeting this pathway might prove beneficial in therapy.

Interestingly, different molecular pathways with druggable targets have been reported linking oncogenic Ras to NF- $\kappa \mathrm{B}$ activation. Chien et al [37] demonstrated that activation of TBK1 by RalB, a Ras effector, is required for Ras-induced transformation. Barbie et al [24] have shown that TBK1 loss leads to synthetic lethality of a variety of KRAS transformed cells. Recently, our 
lab has shown that in pancreatic cancer KRAS utilizes GSK $3 \alpha$ to promote both canonical and non-canonical NF- $\kappa \mathrm{B}$ activation [38]. Duran et al [25] demonstrated that activation of NF- $\kappa \mathrm{B}$ by KRAS involves p62-mediated TRAF6 ubiquitination and activation of IKK. Interestingly, TRAF6 has been shown to be amplified in lung cancers and to function as an oncogene required for Ras-induced transformation [39]. Loss of p62, not only reduces tumor formation in a KRAS-induced lung cancer mouse model [25], but has also been implicated in sustaining NF- $\mathrm{B}$ activity induced by KRAS-IL1 $\alpha$ in pancreatic cancer [27].

Given the above mentioned data linking KRAS to activation of the canonical IKK complex in lung cancer, and given that we had previously shown that increased $\mathrm{NF}-\kappa \mathrm{B}$ activity in KRAS-driven mouse lung tumors were associated with increased phosphorylation of $\mathrm{I} \kappa \mathrm{B} \alpha$, and that KRAS-induced NF- $\kappa \mathrm{B}$ activity in lung cells required IKK $\beta$ [23], the main catalytic subunit of the canonical IKK complex, we hypothesized that a reasonable druggable target in the KRAS-induced NF- $\mathrm{BB}$ activation pathway in lung cancer would be the IKK $\beta$ kinase. Recently, further corroborating our hypothesis, Xia et al [28] have demonstrated that genetic deletion of IKK $\beta$ reduces lung tumorigenesis in a mouse model. Another important consideration is that, even though NF- $\kappa \mathrm{B}$ is ubiquitously expressed, under normal conditions it is usually present in an inactive form. NF- $\kappa \mathrm{B}$ activation is important mainly under stress conditions such as during the inflammatory and innate immune responses. Therefore, systemic NF$\kappa \mathrm{B}$ inhibition therapy (by blocking IKK $\beta$ activity) has the potential to have tolerable side effects and thus provide a broader therapeutic window.

In order to test IKK $\beta$ inhibition therapy as an approach to treat KRAS-induced lung cancer we used CmpdA, a highly specific IKK $\beta$ inhibitor [29]. Using this inhibitor, we had previously shown that it blocks $\mathrm{NF}-\kappa \mathrm{B}$ activity in KRAS-transformed primary lung cells (SAKRAS) cells and H358 cells [23]. Here, we demonstrated that CmpdA inhibits NF- $\kappa$ B activity in other KRAS positive lung cancer cell lines as well (Fig. 1A). While CmpdA is a highly specific IKK $\beta$ inhibitor, it has been published that CmpdA has an approximately 70-fold lower activity on IKK $\alpha$ [29]. Even though we believe that the major effect of CmpdA is on IKK $\beta$, we cannot rule out that it may also suppress the activity of IKK $\alpha$.

Interestingly, $\mathrm{NF}-\kappa \mathrm{B}$ activity was inhibited in these cells by siRNA to either IKK $\beta$ or IKK $\alpha$ (Supplementary Fig. S1). While the result with knockdown of IKK $\beta$ was not surprising, the result with knockdown of IKK $\alpha$ was surprising since it is widely considered that IKK $\beta$ is dominant in the canonical $\mathrm{NF}-\kappa \mathrm{B}$ pathway [30]. Nonetheless, we had previously found that IKK $\alpha$ is involved in canonical NF- $\kappa \mathrm{B}$ activation downstream of Her2/ErbB2 [40]. Additionally, knockdown of IKK $\alpha$ in H358 cells does not affect p100 processing (not shown), but it decreases $\mathrm{I} \kappa \mathrm{B} \alpha$ phosphorylation (Fig. 1C), indicating that in these cells IKK $\alpha$ is largely affecting canonical NF$\kappa \mathrm{B}$ signaling.

Interestingly, CmpdA treatment reduced cell growth leading to a cytostatic effect. This effect was not only dependent on KRAS status as expected (Fig. 2), but also dependent on loss or altered function of the tumor suppressor p53 (Fig. 3). We have shown that inhibition of p53 expression in p53 WT lung cancer cells promotes sensitivity to CmpdA treatment and that p53 re-expression reverses this effect (Fig.3). In addition, p53 knockout HCT116 colon cancer cells, which harbor oncogenic KRAS, are also more sensitive to CmpdA treatment than p53 WT HCT116 cells (Supplementary Fig. S2). This p53 dependency was unexpected, as we have shown that targeting p65/RELA in a p53 competent KRAS-induced lung cancer mouse model reduces tumorigenesis [23] and loss of IKK $\beta$ in a p53 competent RAS-induced melanoma model [26] or in a p53 competent KRAS-induced pancreatic cancer model [27] also reduces tumorigenesis. One explanation for this dependency on p53 status is that, even though KRAS activates NF- $\mathrm{B}$, loss of p53 has been shown to further enhance NF- $\kappa \mathrm{B}$ activation by posttranslational activation of IKK $\beta$ [31]. In fact, Meylan et al [22] showed robust NF- $\kappa \mathrm{B}$ activation in KRAS positive cells upon loss of p53. It is possible that the KRASinduced NF- $\kappa$ B activity level in these p53 WT lung cells is not sufficient to render them intrinsically sensitive to CmpdA treatment in these in vitro studies. In fact, we have shown that inhibition of p53 expression in human and murine lung cancer cells leads to enhanced NF-B activity and likewise, that expression of p53 in p53 null H358 cells reduces NF- $\kappa$ B activity (Fig.3). We note that HCT116 p53 ${ }^{\mathrm{WT}}$ cells do exhibit a level of sensitivity to CmpdA, which may be due to the fact that these cells have low p16 expression, which has been published to suppress NF$\kappa \mathrm{B}$ [41]. It is not possible to predict how p53 WT KRASinduced lung tumors would respond to IKK $\beta$ targeting in situ, as all in vivo experiments targeting this kinase in lung cancer were performed in models with disrupted p53 function $[28,42]$. We propose that combined activation of KRAS and loss of p53 in lung tumor cells would lead to enhanced IKK activity and to increased CmpdA sensitivity in vivo.

In order to investigate if IKK $\beta$ inhibition therapy would be effective in vivo, we treated $\mathrm{KRAS}^{\mathrm{G} 12 \mathrm{D} / \mathrm{p} 53 \Delta}$ mice with CmpdA. CmpdA not only inhibited IKK activity in lung tumors, but also significantly reduced tumor burden, tumor proliferation and slowed tumor progression (Fig. 5). In accordance with our data, Xue et al [42] demonstrated that treatment of $\mathrm{KRAS}^{\mathrm{G} 12 \mathrm{D} / \mathrm{p} 53 \Delta}$ mice treated with bortezomib, a proteassome inhibitor that prevents degradation of $\mathrm{I} \kappa \mathrm{B} \alpha$, also reduces tumor growth. Although proteasome inhibition leads to complex cellular phenotypes, IKK inhibitors were also effective in prolonging survival of KRAS induced lung tumor models $[28,42]$. Finally, genetic targeting of IKK $\beta$ in melanoma, 
pancreatic and lung cancer mouse models also affected the kinetic of tumor development [26-28]. These results, together with ours, suggest that therapeutic strategies aimed at blocking NF- $\kappa \mathrm{B}$ activity should prove beneficial for KRAS-induced lung cancer therapy, especially in patients with simultaneous loss or mutation of $\mathrm{p} 53$.

Interestingly, whereas loss of NF- $\kappa$ B p65/RELA in KRAS-induced lung tumors is associated with an apoptotic response [23], inhibition or loss of IKK $\beta$ does not induce apoptosis in cell lines or in KRAS induced lung tumors (Supplementary Fig. S3 and Fig. 4, [28]). This puzzling result can be explained by recent findings demonstrating that kinase inhibition can lead to activation of compensatory pathways that can affect the biological readout [43-46]. In this regard, targeting NF$\kappa \mathrm{B}$ directly through p65/RELA loss [23] or expression of a degradation resistant form of $\mathrm{I} \kappa \mathrm{B} \alpha$ [22] may lead to an apoptotic response, whereas targeting the upstream IKK $\beta$ kinase could activate compensatory pathways that would eliminate this response, and could even explain the acquisition of therapy resistance, which was observed upon treatment with the IKK inhibitor Bay-117082 [42]. Nonetheless, the antiproliferative effect of IKK $\beta$ targeting is retained.

In addition to promoting intrinsic tumor cell proliferation, RAS oncoproteins can influence the tumor microenvironment by inducing secretion of proinflammatory and pro-angiogenic cytokine IL-8 $[35,47]$. It is well known that $I L-8$ is a NF- $\mathrm{BB}$ target gene $[48,49]$ and we have shown that in KRAS-transformed lung cells, $I L-8$ expression depends on IKK $\beta$ [23]. Here we show that IKK $\beta$ inhibition by CmpdA treatment affects the microenvironment of KRAS-induced lung tumors, reducing tumor-related inflammation and angiogenesis (Supplementary Fig. S4). It remains to be determined if CmpdA causes a reduction in the ability of tumor cells to recruit inflammatory and endothelial cells to the tumors or if it directly affects activation and migration of these cells. It is likely that both possibilities coexist. In the case of inflammation, CmpdA has been shown to have anti-inflammatory effects [33], and genetic loss of IKK $\beta$ in mouse lung tumors is associated with a reduced inflammatory infiltrate [28]. In the case of angiogenesis, expression of a dominant negative form of IKK $\beta$ in endothelial cells inhibits tube formation [50]. Even though previous studies with genetic targeting of IKK $\beta$ in tumor mouse models did not address the effect of IKK $\beta$ deletion on tumor angiogenesis, it has been demostrated that IKK $\beta$ can promote tumor angiogenesis by phosphorylating TSC1 and activating mTOR in tumor cells [51]. Finally, we cannot disregard the possibility that the reduced vessel density observed results from reduced tumor-associated inflammation, as tumor associated macrophages can further stimulate secretion of pro-angiogenic cytokines by tumor cells [52].

Interestingly, even though treatment of mice with the
IKK $\beta$ inhibitor TPCA-1 was associated with toxicity [28], this study shows that CmpdA is well tolerated in mice. In fact, CmpdA is a highly specific IKK $\beta$ inhibitor, which can inhibit IKK $\alpha$ at a 70-fold higher concentration, but does not affect activity of other related serine threonine kinases including TBK1 and IKKe [29]. Other studies using this inhibitor also report that $\mathrm{CmpdA}$ is not associated with significant toxicity in mice $[29,33,53]$, indicating CmpdA as a promising IKK $\beta$ inhibitor to be used in clinical trials for cancer therapy.

It is important to acknowledge that CmpdA treatment does not lead to complete tumor regression. Alternative pharmacological and genetic approaches to target the NF- $\kappa \mathrm{B}$ pathway in KRAS-driven lung cancer also do not completely eliminate tumorigenesis $[23,28]$. Interestingly, we have shown that loss of KRAS led to greater reduction of cell growth and proliferation than loss of either IKK $\beta$ or IKK $\alpha$, suggesting that KRAS activates additional and/or alternative pathways that contribute to cell proliferation. Effective KRAS targeting will likely involve combined inhibition of these pathways.

In conclusion, we have identified IKK $\alpha$ and IKK $\beta$ as promising druggable targets to inhibit NF- $\kappa \mathrm{B}$ activity downstream of KRAS and loss of p53. We have also demonstrated in a preclinical model of KRAS-induced lung cancer with loss of p53 that IKK $\beta$ inhibition therapy is safe in mice and, even though it is not curative, it shows efficacy in slowing tumor growth. Taken together, our results indicate that IKK $\alpha$ or IKK $\beta$ inhibition therapy might prove to be a promising approach to be validated in clinical trials, particularly using combination strategies to treat KRAS-induced lung cancer with loss of the tumor suppressor p53.

\section{MATERIALS AND METHODS}

\section{Cell culture}

Cell passages were kept to a minimum and no cells were passaged continuously for more than six months. Low passage SALEB and SAKRAS cells were cultured in serum-free bronchial epithelium growth medium (BEGM, Clonetics-Lonza, Allendale, NJ). These cells were originally selected in medium containing a triple antibiotic cocktail and subsequently characterized by real-time PCR for expression of the genes used for immortalization and transformation [54]. Short Tandem Repeat-DNA profile authenticated NCI-H358, A549, NCI-H460 and NCI-H1792 cells were obtained from ATCC (Manassas, VA) and maintained in RPMI 1640 (Invitrogen, Carlsbad, CA) supplemented with 10\% FBS (Sigma-Aldrich, St. Louis, MO). KE67 cells were generated and characterized in the laboratory [23]. KPF54 cells were generated as described for KE67 cells from 
lung tumors of oncogenic KRAS inducible Lox-StopLox (LSL) Kras ${ }^{\mathrm{G} 12 \mathrm{D}}$ mice with conditional inactivation of p53 [32]. Their origin was authenticated by PCR of the excised Kras and p53 alleles. They were maintained in Dulbecco's Modified Eagle's Medium (DMEM, Invitrogen, Carlsbad, CA) supplemented with 10\% FBS and $0.5 \mathrm{mM}$ 2-mercaptoethanol (both from Sigma-Aldrich, St. Louis, MO).

\section{Transfections and Reporter Assays}

siRNA transfections were performed as previously described [55] with $100 \eta \mathrm{M}$ of either a non-targeting siRNA control or siRNA smart pools targeting p53, IKK $\beta$, IKK $\alpha$ or KRAS (Dharmacon/Thermo Scientific, Pittsburgh, PA). For p53 knockdown studies in murine cells, we used $50 \eta \mathrm{M}$ of p53 siRNA or non-targeting control siRNA (Ambion/Life Technologies, Grand Island, NY). Plasmid DNA transfection using a pcDNA-p53 expression vector (Addgene, Cambridge, MA) were performed with Lipofectamine LTX (Life technologies, Grand Island, NY) according to the manufacturer's instructions. Combined siRNA/plasmid transfections were performed sequentially, with the plasmid transfection performed $48 \mathrm{~h}$ after the siRNA transfection. Dual Luciferase Reporter assays were performed as described [55]. For pharmacological studies, cells were treated with CmpdA or vehicle control as indicated (see figure legends). Relative light units were measured on an Lmax Microplate Luminometer (Molecular Devices, Sunnyvale, CA).

\section{3-(4,5-dimethylthiazol-2-yl)-5-(3- carboxymethoxyphenyl)-2-(4-sulfophenyl)-2H- tetrazolium salt (MTS) assay}

The MTS assay was performed using the Cell Titer 96 AQueous One Solution Cell Proliferation assay (Promega, Madison, WI) according to the manufacturer's protocol. The reduction of MTS to formazan was measured colorimetrically at 490nm on a VersaMax Microplate Reader (Molecular Devices, Sunnyvale, CA).

\section{BrdU Incorporation Assay}

BrdU incorporation was evaluated using the BrdU Cell Proliferation Assay (EMD Millipore, Billerica, MA) following the manufacturer's instructions. Cells were incubated with $\mathrm{BrdU}$ for $2 \mathrm{~h}$ prior to harvesting for analysis. BrdU incorporation was measured colorimetrically on a VersaMax Microplate Reader (Molecular Devices, Sunnyvale, CA) at 450nm.

\section{Western Blotting}

Western Blotting was performed as described [55]. The antibodies used and respective catalog numbers were as follows: anti-IKK $\beta$ (05-535), anti-IKK $\alpha$ (05536) and anti-pan-RAS (OP-40) were from EMD Millipore (Billerica, MA); anti-I $\kappa \mathrm{B} \alpha$ (4812) and antiphospho(s32/36)I $\mathrm{B} \alpha$ (9246) were from Cell Signaling (Danvers, MA); we also used anti-GAPDH (sc-25778) and anti-p53 antibodies (cs-2527, Cell Signaling, Danvers, MA and sc-98, Santa Cruz Biotechnology, Santa Cruz, CA).

\section{Animal husbandry and Cre-expressing adenovirus (adenocre) administration}

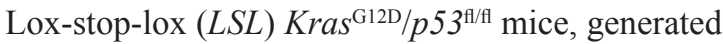
by crossing strains B6.129S4-Kras ${ }^{\text {tm } 4 y j}$ and B6.129P2$\operatorname{Trp} 53^{\operatorname{tm} 1 B r n 31}$ were housed in pathogen-free conditions according to the protocols approved by the UNC Institutional Animal Care and Use Committee. Lung tumor induction was performed by intranasal administration of $1 \times 10^{7}$ plaque forming units (pfus) of adenocre (Gene Transfer Vector Core, University of Iowa, Iowa City, IA) in selected animals at 8 weeks of age, as described [56].

\section{In vivo Administration of CmpdA}

$10 \mathrm{mg} / \mathrm{kg}$ of IKK $\beta$ inhibitor CmpdA (Bayer, Pittsburgh, PA, [29]) was administered intraperitoneally daily for 4 weeks, starting at 8 weeks post-infection. Dimethyl sulfoxide (DMSO, Sima-Aldrich, St. Louis, MO) was used as vehicle control. To minimize the risk of DMSO-induced toxicity, we used CmpdA at a concentration of $5 \mathrm{mg} / \mathrm{mL}$ to reduce the volume used to perform injections. All mice were euthanized at the end of treatment (12 weeks post-infection).

\section{Histopathological analysis}

Mice were euthanized by intraperitoneal administration of $250 \mathrm{mg} / \mathrm{kg}$ of freshly prepared avertin followed by surgical resection of the portal vein. Lungs were perfused with saline and inflation-fixed overnight with formalin 10\%. Fixed tissues were embedded in paraffin, sectioned at 5 micrometer thickness and stained with hematoxylin/eosin.

\section{Terminal deoxynucleotidyl transferase-mediated dUTP nick end labeling (TUNEL) assay}

Tissue sections were deparaffinized, rehydrated, and stained according to the ApopTag Plus In Situ Apoptosis Detection kit (EMD Millipore, Billerica, MA) instructions. 


\section{Immunohistochemistry}

Formalin-fixed, paraffin-embedded tissue sections were stained with rat monoclonal anti-KI67 antibody (Clone TEC3, DakoCytomation, Carpinteria, CA) diluted $1: 25$, or mouse monoclonal anti-phospho-IкB $\alpha$-Ser32/36 (9246, Cell Signaling, Danvers, MA) diluted 1:100 using the Rat Vector Elite ABC Kit (Vector Laboratories, Burlingame, CA) or the Mouse on Mouse (M.O.M) Peroxidase Kit (Vector Laboratories, Burlingame, CA), following the manufacturer's protocol. Quantitation of staining results was perfomed using ImageJ software to count positive cells.

\section{Tumor number and grade analysis}

Slides from each lung lobe (same orientation and level section used for each lobe) were scored for tumor number, area and grade blindly. For tumor number and area, low magnification pictures were taken in a Olympus BX61 upright fluorescence microscope (Olympus, Center Valley, PA) and images were analyzed using ImajeJ software. For analysis of tumor grade, slides were scanned with a 40X magnification resolution using a Scanscope CS Digital Scanner (Aperio, Vista, CA). Tumors were scored using ImageScope software (Aperio, Vista, CA). Each tumor was given a score of 1 to 5 based on previously described criteria [32].

\section{Statistics}

All values are presented either as mean $\pm 1 \mathrm{SD}$ or as representative images of at least three independent experiments. In the case of animal studies, at least three mice of each different genotype were analyzed. All comparisons were made using the unpaired Student $t$ test for samples with unequal variance. Differences were considered statistically significant at $p \leq 0.05$ (indicated by asterisks).

\section{CONFLICTS OF INTEREST}

The authors have no conflits of interest to disclose

\section{ACKNOWLEDGEMENTS}

This work was supported by a grant from the Doctor's Cancer Foundation (DCF), a Young Clinical Scientist Award (YCSA 072165) from the Flight Attendant Medical Research Institute (FAMRI) and a Young Investigator Grant (2010/52685-9) from the Fundação de Apoio à Pesquisa do Estado de São Paulo (FAPESP) to D.S.B. and by NIH grants (CA73756 and CA75080), a National Lung Cancer Partnership/Lungevity Award, and the Samuel Waxman Cancer Research Foundation to A.S.B. We thank Dr. Yanping Zhang for providing HCT116-p53 WT and HCT116-p53 knockout cells and Dr. Scott Randell for providing the SALEB and SAKRAS cells.

\section{REFERENCES}

1. Jemal A, Siegel R, Xu J, Ward E. Cancer statistics, 2010. CA Cancer J Clin 2010;60:277-300.

2. Zhang Z, Stiegler AL, Boggon TJ, et al. EGFR-mutated lung cancer: a paradigm of molecular oncology. Oncotarget 2010;1:497-514.

3. Gerber DE, Minna JD. ALK inhibition for non-small cell lung cancer: from discovery to therapy in record time. Cancer Cell 2010;18:548-51.

4. Westra WH, Slebos RJ, Offerhaus GJ, et al. K-ras oncogene activation in lung adenocarcinomas from former smokers. Evidence that K-ras mutations are an early and irreversible event in the development of adenocarcinoma of the lung. Cancer 1993;72:432-8.

5. Gao HG, Chen JK, Stewart J, et al. Distribution of p53 and K-ras mutations in human lung cancer tissues. Carcinogenesis 1997; 18:473-8.

6. Vahakangas KH, Bennett WP, Castren K, et al. P53 and K-ras Mutations in Lung Cancers from Former and NeverSmoking Women. Cancer Res 2001;61:4350-6.

7. Adjei AA. K-ras as a target for lung cancer therapy. J Thorac Oncol 2008;3:S160-3.

8. Linardou H, Dahabreh IJ, Kanaloupiti D, et al. Assessment of somatic k-RAS mutations as a mechanism associated with resistance to EGFR-targeted agents: a systematic review and meta-analysis of studies in advanced non-smallcell lung cancer and metastatic colorectal cancer. Lancet Oncol 2008;9:962-72.

9. Friday BB, Adjei AA. K-ras as a target for cancer therapy. Biochim Biophys Acta 2005;1756:127-44.

10. Engelman JA, Chen L, Tan X, et al. Effective use of PI3K and MEK inhibitors to treat mutant Kras G12D and PIK3CA H1047R murine lung cancers. Nat Med 2008;14:1351-6.

11. Lim KH, O'Hayer K, Adam SJ, et al. Divergent roles for RalA and RalB in malignant growth of human pancreatic carcinoma cells. Curr Biol 2006;16:2385-94.

12. Bodemann BO, White MA. Ral GTPases and cancer: linchpin support of the tumorigenic platform. Nat Rev Cancer 2008;8:133-40.

13. Yamamoto Y, Gaynor RB. IkappaB kinases: key regulators of the NF-kappaB pathway. Trends Biochem Sci 2004;29:72-9.

14. Gilmore TD. Introduction to NF-kappaB: players, pathways, perspectives. Oncogene 2006;25:6680-4.

15. Basseres DS, Baldwin AS. Nuclear factor-kappaB and inhibitor of kappaB kinase pathways in oncogenic initiation 
and progression. Oncogene 2006;25:6817-30.

16. Perkins ND. Integrating cell-signalling pathways with NF-kappaB and IKK function. Nat Rev Mol Cell Biol 2007;8:49-62.

17. Hayden MS, Ghosh S. NF- $\kappa B$, the first quarter-century: remarkable progress and outstanding questions. Genes Dev 2012;26:203-34.

18. Staudt LM. Oncogenic activation of NF-kappaB. Cold Spring Harb Perspect Biol 2010;2:a000109.

19. Shen RR, Hahn WC. Emerging roles for the non-canonical IKKs in cancer. Oncogene 2011;30:631-41.

20. Finco TS, Westwick JK, Norris JL, Beg AA, Der CJ, Albert SS. Oncogenic Ha-Ras-induced signaling activates NF-kappa B transcriptional activity, which is required for cellular transformation. J. Biol. Chem 1997;272:24113-6.

21. Mayo MW, Wang C-Y, Cogswell PC, et al. Requirement of NF-kappaB activation to suppress p53-independent apoptosis induced by oncogenic Ras. Science 1997;278:1812-5.

22. Meylan E, Dooley AL, Feldser DM, et al. Requirement for NF-kappaB signalling in a mouse model of lung adenocarcinoma. Nature 2009;462:104-7.

23. Bassères DS, Ebbs A, Levantini E, Baldwin AS. Requirement of the NF-kappaB subunit p65/RelA for K-Ras-induced lung tumorigenesis. Cancer Res 2010;70:3537-46.

24. Barbie DA, Tamayo P, Boehm JS, et al. Systematic RNA interference reveals that oncogenic KRAS-driven cancers require TBK1. Nature 2009;462:108-12.

25. Duran A, Linares JF, Galvez AS, et al. The signaling adaptor p62 is an important NF-kappaB mediator in tumorigenesis. Cancer Cell 2008;13:343-54.

26. Yang J, Splittgerber R, Yull FE, et al. Conditional ablation of Ikk $\beta$ inhibits melanoma tumor development in mice. J Clin Invest 2010;120:2563-74.

27. Ling J, Kang $\mathrm{Y}$, Zhao R, et al. KrasG12D-induced IKK $2 / \beta / \mathrm{NF}-\kappa \mathrm{B}$ activation by IL- $1 \alpha$ and $\mathrm{p} 62$ feedforward loops is required for development of pancreatic ductal adenocarcinoma. Cancer Cell 2012;21:105-20.

28. Xia Y, Yeddula N, Leblanc M, et al. Reduced cell proliferation by IKK2 depletion in a mouse lung-cancer model. Nat Cell Biol 2012;14:257-65.

29. Ziegelbauer K, Gantner F, Lukacs NW, et al. A selective novel low-molecular-weight inhibitor of IkappaB kinasebeta (IKK-beta) prevents pulmonary inflammation and shows broad anti-inflammatory activity. Br J Pharmacol 2005;145:178-92.

30. Li ZW, Chu W, Hu Y, et al. The IKKbeta subunit of IkappaB kinase (IKK) is essential for nuclear factor kappaB activation and prevention of apoptosis. J Exp Med 1999;189:1839-45.

31. Kawauchi K, Araki K, Tobiume K, Tanaka N. p53 regulates glucose metabolism through an IKK-NF-kappaB pathway and inhibits cell transformation. Nat Cell Biol 2008;10:611-
8.

32. Jackson EL, Olive KP, Tuveson DA, et al. The Differential Effects of mutant p53 alleles on advanced murine lung cancer. Cancer Res 2005;65:10280-8.

33. Murata T, Shimada M, Sakakibara S, et al. Synthesis and structure-activity relationships of novel IKK-beta inhibitors. Part 3: Orally active anti-inflammatory agents. Bioorg Med Chem Lett 2004;14:4019-22.

34. Karin M, Greten FR. NF-kappaB: linking inflammation and immunity to cancer development and progression. Nat Rev Immunol 2005;5:749-59.

35. Sparmann A, Bar-Sagi D. Ras-induced interleukin-8 expression plays a critical role in tumor growth and angiogenesis. Cancer Cell 2004;6:447-58.

36. Hanson JL, Hawke NA, Kashatus D, Baldwin AS. The Nuclear factor kappaB subunits RelA/p65 and c-Rel potentiate but are not required for Ras-induced cellular transformation. Cancer Res 2004;64:7248-55.

37. Chien Y, Kim S, Bumeister R, et al. RalB GTPase-mediated activation of the IkappaB family kinase TBK1 couples innate immune signaling to tumor cell survival. Cell 2006; 127:157-70.

38. Bang D, Wilson W, Ryan M, Yeh JJ, Baldwin AS. GSK-3 $\alpha$ promotes oncogenic KRAS function in pancreatic cancer via TAK1-TAB stabilization and regulation of noncanonical NF-кB. Cancer Discov 2013;3:690-703.

39. Starczynowski DT, Lockwood WW, Delehouzee S, et al. TRAF6 is an amplified oncogene bridging the RAS and NF- $\kappa$ B pathways in human lung cancer. J Clin Invest 2011;121:4095-105.

40. Merkhofer EC, Cogswell P, Baldwin AS. Her2 activates NF-kappaB and induces invasion through the canonical pathway involving IKKalpha. Oncogene 2010;29:1238-48.

41. Becker TM, Rizos H, de la Pena A, et al. Impaired inhibition of NF-kappaB activity by melanoma-associated p16INK4a mutations. Biochem Biophys Res Commun 2005;332:8739.

42. Xue W, Meylan E, Oliver TG, et al. Response and resistance to NF- $\kappa \mathrm{B}$ inhibitors in mouse models of lung adenocarcinoma. Cancer Discov 2011;1:236-47.

43. Chandarlapaty S, Sawai A, Scaltriti M, et al. AKT inhibition relieves feedback suppression of receptor tyrosine kinase expression and activity. Cancer Cell 2011;19:58-71.

44. Rodrik-Outmezguine VS, Chandarlapaty S, Pagano NC, et al. mTOR kinase inhibition causes feedback-dependent biphasic regulation of AKT signaling. Cancer Discov 2011;1:248-59.

45. Lito P, Pratilas CA, Joseph EW, et al. Relief of profound feedback inhibition of mitogenic signaling by RAF inhibitors attenuates their activity in BRAFV600E melanomas. Cancer Cell 2012;22:668-82.

46. Duncan JS, Whittle MC, Nakamura K, et al. Dynamic reprogramming of the kinome in response to targeted MEK inhibition in triple-negative breast cancer. Cell 
2012;149:307-21.

47. Sunaga N, Imai H, Shimizu K, et al. Oncogenic KRASinduced interleukin-8 overexpression promotes cell growth and migration and contributes to aggressive phenotypes of non-small cell lung cancer. Int J Cancer 2012;130:1733-44.

48. Stein B, Baldwin AS. Distinct mechanisms for regulation of the interleukin- 8 gene involve synergism and cooperativity between C/EBP and NF-kappa B. Mol Cell Biol 1993;13:7191-8.

49. Hoffmann E, Dittrich-Breiholz O, Holtmann H, Kracht M. Multiple control of interleukin-8 gene expression. J Leukoc Biol 2002;72:847-55.

50. Oitzinger W, Hofer-Warbinek R, Schmid JA, Koshelnick $\mathrm{Y}$, Binder BR, de Martin R. Adenovirus-mediated expression of a mutant IkappaB kinase 2 inhibits the response of endothelial cells to inflammatory stimuli. Blood 2001;97:1611-7.

51. Lee DF, Kuo HP, Chen CT, et al. IKK beta suppression of TSC1 links inflammation and tumor angiogenesis via the mTOR pathway. Cell 2007;130:440-55.

52. Ono M. Molecular links between tumor angiogenesis and inflammation: inflammatory stimuli of macrophages and cancer cells as targets for therapeutic strategy. Cancer Sci 2008;99:1501-6.

53. Wysong A, Couch M, Shadfar S, et al. NF- $\kappa$ B inhibition protects against tumor-induced cardiac atrophy in vivo. Am J Pathol 2011;178:1059-68.

54. Lundberg AS, Randell SH, Stewart SA, et al. Immortalization and transformation of primary human airway epithelial cells by gene transfer. Oncogene 2002;21:4577-86.

55. Wilson W, Baldwin AS. Maintenance of constitutive IkappaB kinase activity by glycogen synthase kinase3alpha/beta in pancreatic cancer. Cancer Res 2008;68:815663.

56. Jackson EL, Willis N, Mercer K, et al. Analysis of lung tumor initiation and progression using conditional expression of oncogenic K-ras. Genes Dev 2001;15:3243-8. 